\title{
The Study of Water in the Municipality of Salvatierra, Guanajuato, Mexico. An Approach from Environmental Sociology
}

\author{
Alberto Valdes Cobos \\ University of Guanajuato \\ Department of Cultural, Demographic and Political Studies \\ Celaya-Salvatierra \\ Rigoberto Sandoval Contreras \\ University of Guadalajara \\ University Center of the Valleys \\ Ameca, Jalisco
}

\begin{abstract}
Summary
The objective of this work is to propose a study from the constructivist environmental sociology of water in the municipality of Salvatierra, Guanajuato, Mexico, assuming that exist a sociopolitical construction of pollution, overexploitation and the scarcity of water that is linked to a several rural development policies that could be reconstructed based on the way that a variety of social actors perceive and build them. It is assumed that these constructions are an expression of values, norms and social and political interests prevailing in a range of social actors and in the municipal authorities in charge of promoting rural development based on a specific social construction on the use, management and socio-environmental problems of water.
\end{abstract}

Keywords: water crisis, environmental sociology, territory, rural development.

\section{Introduction}

The present work is derived from the research project titled The social construction of the problem of water and rural development in the municipality of Salvatierra, approved on December 2, 2016 by the Divisional Council of the Division of Social and Administrative Sciences of the Campus Celaya-Salvatierra of the University of Guanajuato. It should be noted that this research project is part of the research lines of rural development and environmental sociology.

The complex problem of water is a physical, environmental and social issue from the interest of agronomists as well as ecologists and social scientists. Overexploitation, pollution and scarcity of water are due to a series of anthropogenic causes of a political, economic, demographic and cultural nature that affect human groups and societies at a local, national and global level. On the other hand, the commodification of the vital liquid is increasingly the cause of political conflicts on the part of governments, companies and civil society organizations, which are likely to intensify their struggles in the coming decades, as the population increases, economic growth, the neoliberal privatizing pressures and the catastrophic effects of droughts, staging neomalthusian wars for the political and territorial control of water.

The objective of this work is to propose a study of water in the municipality of Salvatierra from the perspective of constructivist environmental sociology, a perspective that is absent in the few studies that have been carried out on water in that municipality. In the first section, the socio-environmental and global water crisis is exposed; the proposal of the water democracy of Vandana Shiva and the privatizing threats of neoliberal globalization. In the second section, an overview of the water problem at the national level and the State of Guanajuato is presented. In the third section, the problem of water in the municipality of Salvatierra is described. In the fourth section, the relationship between water and rural development is explored from the constructivist environmental sociology. Finally, in the fifth section, some conclusions are presented about the complex water issue in the State of Guanajuato and the municipality of Salvatierra. 


\section{The Socio-Environmental and Global Water Crisis}

As the effects of global climate change deepen and the processes of water privatization intensify, debates over water as a human right increase; the right to water of new and future generations; the processes of pollution and overexploitation of water; the risks to human health from the consumption of contaminated water; the relationship between environmental education and water culture; water management by women and the geopolitics of the developed world with respect to the right to water, among others. The complex issue of water has a strategic, territorial and public policy importance at the local, national and global levels, which interests governments and multinational companies, as well as social movements, universities and research centers. Its lack, quality and availability costs are increasingly the cause of disputes between countries, groups and human societies of the five continents.

Given the multiple economic, political, socio-cultural and environmental aspects that it entails, water is also a reason for socio-territorial struggles and conflicts where nation-states, cities, peasant communities and indigenous people compete for their political control. Since the 70s of the last century, environmental movements have been fighting for the defense and conservation of natural resources, particularly water as a right to life. But, in addition, the academy has also been added to its inter and multidisciplinary study, which highlights new fields of study such as environmental sociology, political ecology, ecological economics, environmental anthropology, environmental law and environmental history, for cite some examples of hybrid knowledge that seek to address the study of water and its possible public policy solutions.

Currently, we heard about a crisis in civilization, a crisis in development, an environmental crisis, but also a "water crisis", as well as the need to make an integral management of water resources, "in the second half of the 20th century, Water consumption in industrialized countries has multiplied fivefold and the World Meteorological Organization calculates that by 2025 two thirds of humanity can experience situations of "water stress" (Sempere and Riechman, 2004: 121).

For its part, the ecofeminist activist Vandana Shiva points out that solutions to the water crisis cannot come from the market or from multinational corporations, but from movements and organizations of civil society that demand political and ecological solutions, and they have proposed the Charter of Community Environmental Rights, which includes rights to a clean industry, security against harmful exposures, prevention, knowledge, participation, protection and procurement, compensation and sanitation. All of them, indispensable for a water democracy, that defend the right of all citizens to clean water, whose principles are described below:

Water is a gift from nature; 2) water is essential for life; 3) life is closely related by water; 4) water for subsistence purposes must be free; 5) water is limited and can be finished; 6) the water must be preserved; 7) water is a communal property; 8) nobody has the right to destroy and 9) water is irreplaceable (Shiva, 2003, pp. 49-50).

Behind the water crisis, there is a set of neoliberal policies that are inscribed in the model of a corporate globalization, which has brought a series of sociocultural and environmental costs in the living conditions of rural populations. Corporate globalists aim to accelerate these trends. They seek international policies and agreements that safeguard investors and private property, while eliminating barriers to the free movement of goods, money and companies seeking economic opportunity wherever they may be found. They consider that multinational corporations are the most important and effective human institutions, powerful engines of innovation and the creation of wealth that everywhere obstructs the obstacles to human progress and achievements. Neoliberal globalization has several key characteristics that are: a) promotion of hyper growth and unlimited exploitation of environmental resources to feed this growth; b) privatization and commodification of public services and the remaining aspects of global and community commons; c) integration and conversion of national economies, including some with a high degree of independence, to export-oriented production, which is socially and environmentally detrimental, and d) dismantling of public health, social and environmental programs underway (Cavanagh et al., 2003).

\section{The problem of water at the national level and the State of Guanajuato}

According to a study by the Economic Commission for Latin America and the Caribbean (ECLAC, 2010), In rural Mexico, a problem of low water availability is confirmed, which is focused on the northern and central states of the country. 
This problem is clear if it is observed that $92 \%$ of the irrigation area (north, northwest and center) has $32 \%$ of the natural availability of water and produces $85 \%$ of GDP, while the rest (southeast) has $68 \%$ of natural availability of water and only produces $15 \%$ of GDP. The low availability of water in the indicated regions generates pressure for overexploitation. The problem of pressure to overexploitation of the resource manifests itself as strong in the northern zone and very strong in the Valley of Mexico. Also, Guanajuato is the state that concentrates $30 \%$ of the overexploitation of water. In relation to the problem of low water availability, the following causes stand out: a) limited provision of basic services to the communities; b) drought, mainly in the center of the country; c) overexploitation of aquifers: as of the 70s, the number of overexploited aquifers has increased substantially (in 1975 they were 32, 80 in 1985, and 101 in 2008 and there is a very high probability that they will increase to 170) ; d) a quarter of the farmers perform illegal exploitation of wells, and e) the use and waste of resources in agricultural activities. $40.7 \%$ of surface water and $20.5 \%$ of groundwater have an agricultural use. The agricultural sector occupies a total of $77 \%$ of the water, with an average efficiency of $64 \%$, which means that $1 / 3$ of the water is wasted before reaching the crops. As a cause of this waste, the use of unsustainable irrigation technologies was identified (ECLAC, 2010, pp. 48-50).

Regarding water pollution, Lerma Santiago Pacífico, Balsas, Valle de México and Sistema Cutzamala were identified as the regions with the greatest number of basins and bodies of water with a high degree of contamination in terms of biological oxygen demand, chemical oxygen demand and quantity of solids in suspension. Among the causes identified with respect to the pollution problem are:a)Industrial pollution: the problem of water pollution comes from the pollutants of the industrial and service sectors (oil, sugar, chemicals); b) infiltration of agrochemicals: in agricultural areas the recharge of aquifers causes agrochemicals to infiltrate and contaminate water. However, there is no information regarding the size of this problem because, although its existence is recognized in commercial agricultural areas, it is not monitored, and c) water treatment plants working below their installed capacity. Among the main effects of the water pollution problem that were detected are: a) depletion in the availability of water due to its quality, and b) public health problems, due to: (a) pathogenic organisms in direct consumption crops; (b) heavy metals and nitrogen compounds that cause crop toxicity and decrease the quality and health of the products; and (c) dissolved solids (ECLAC, 2010, p.52).

At the state level, the government of Guanajuato in its Government Program 2012-2018. A government with a human face and social sense (2013), recognized as part of the axis of quality of life, the concerns related to the environment such as pollution, the loss of biodiversity, scarcity and water management. Guanajuato is the fourth state with the most overexploitation of aquifers. The rate of national over-exploitation is 1.37 while for the state it is of the order of 1.5; 516 aquifers are overexploited and 9 of them are considered highly overexploited (8.9\% of the national total).

The rapid growth of population and economic development in Guanajuato during the second decade of the twentieth century caused an exponential increase in water demand, so that in parallel increased the number of underground utilities (currently there are approximately 20,000 wells in the state). The State of Guanajuato is located within three hydrographic basins: Lerma-Chapala, the Santiago River and the Pánuco River and within its territory there are 20 aquifer zones. The groundwater balance in Guanajuato shows a deficit for many years, while the demand for surface water exceeds supply (Casillas, Navarrete and Segovia, 2012).

Water is an essential resource for life, the alteration of the dynamics of the hydrological cycle has diminished its availability. In the agricultural sector is wasted mainly by poor irrigation infrastructure, while in the urban area the waste is generated by the poor conditions of its infrastructure and lack of water culture.

\section{The problem of water in the municipality of Salvatierra}

The municipality of Salvatierra is located in the south of the State of Guanajuato, it comprises $1.9 \%$ of its territory, it belongs to Region IV Sur and Subregion 9 within the regional integration. It borders to the north with Jaral del Progreso, Cortázar and Tarimoro; to the east with Tarimoro and Acámbaro; to the south with Acámbaro and the State of Michoacán de Ocampo; to the west with the State of Michoacán de Ocampo, Yuriria, Santiago Maravatío and Jaral del Progreso (IPLANEG, 2012). 
Map.1 Salvatierra. State, regional and subregional location.
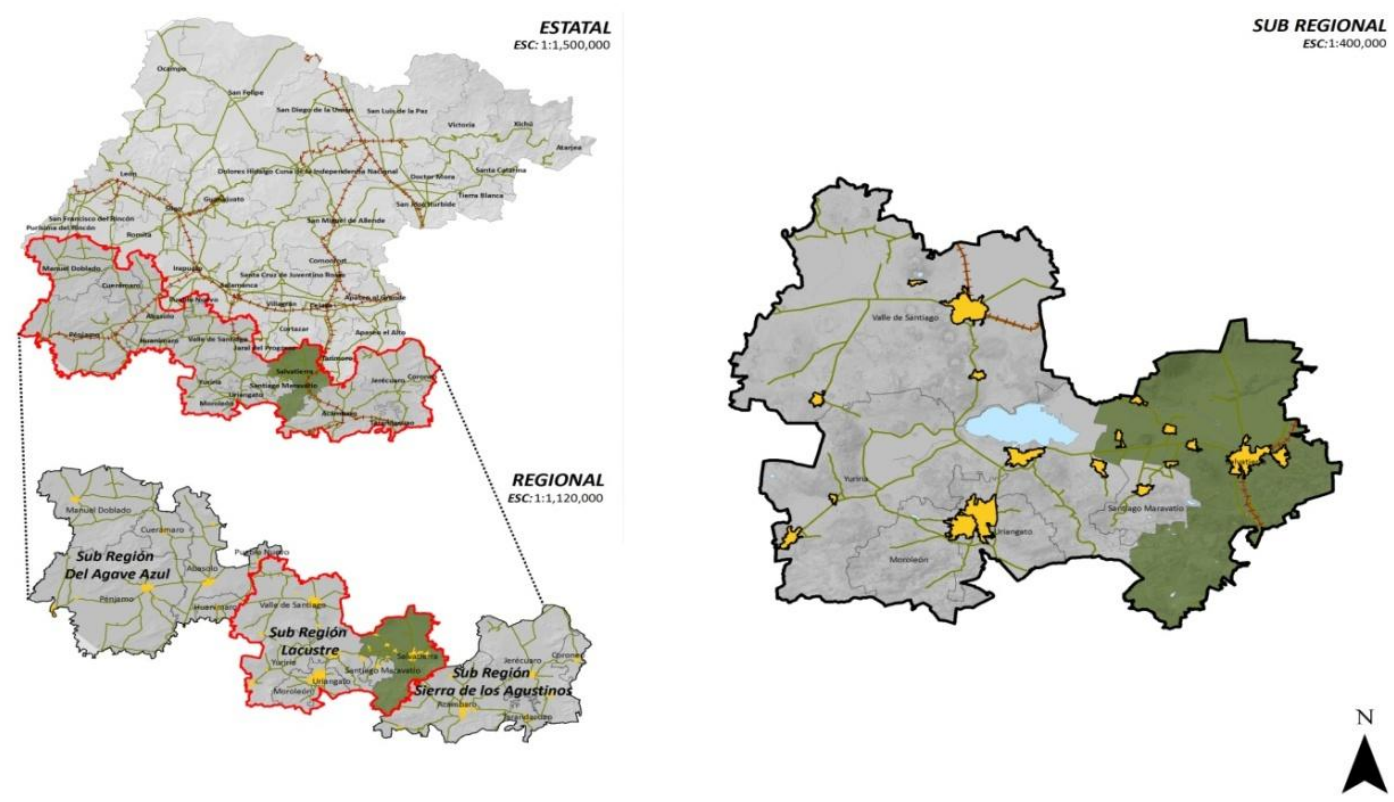

Source: IPLANEG (2012). Propuesta de Plan Municipal Municipio de Salvatierra. Recovered: November 12, 2015. From: seieg.iplaneg.net/pmd/doc/salvatierra/iii.documento/salvatierra_pmd.doc

Salvatierra has a total of 82 locations, of which 6 have a population of more than 2,500 inhabitants, that are consideredurban; the municipal seat Salvatierra (37,203 inhabitants), theUrireolocality (8,679 inhabitants), San Nicolás de los Agustinos (7,148 inhabitants), San Pedro de los Naranjos (4,494 inhabitants), El Sabino (4,095 inhabitants) and finallyMaravatío del Encinal(3,398 inhabitants). The municipality has a population density of 163.7 inhabitants per square kilometer. According to the 2010 General Population and Housing Census, the population settled in Salvatierra is 97,054 inhabitants, which represents 1.8\% of the state population.

According to a SWOT analysis carried out in 2012, in Salvatierra, a high rate of women victims of sexual crimes, government corruption, drug trafficking, migration, population with educational backwardness, localities without rural telephony service, lack of support and advice in the agricultural land, problems with climate issues in agricultural production units, lack of spaces for final disposal of urban solid waste, aquifer (s) over-exploited and lack of a culture of care and efficient use of water in the agricultural lands and in the city, low coverage of wastewater treatment. It is worth mentioning that the aquifer to which the municipality belongs is overexploited, about $25.1 \%$ of the water extraction is carried out from deep wells, and within the municipality $65.2 \%$ of agricultural production units have land channels as an irrigation system, and only $8.7 \%$ have updated irrigation systems, and that the coverage of wastewater treatment is minimal (IPLANEG, 2012).

The use of agricultural land of $70 \%$ of the municipal surface, the pasture area is $4.9 \%$, the urban area $3.6 \%$, the forest area $20 \%$ and forest $1.2 \%$. The surface of the municipality understands 581.82 square kilometers, equivalent to $1.66 \%$ of the territory of the state. The economic sector that predominates in the municipality is the tertiary one. Currently the population is concentrated in the commerce sector to the detriment of agricultural activity. Salvatierra produces a wide variety of agricultural products such as garlic, forage oats, broccoli, peanuts, squash, sweet potato, barley, onion, peas, chili, cabbage, cauliflower, chickpeas, beans, lettuce, corn, melon, cucumber, watermelon, tomato, wheat, carrot, gladiola, sorghum, alfalfa, sugar cane, chayote, peach, asparagus, strawberry, guava, cactus, grass, grapes. As we can see, water is a vital resource for the agricultural economy and for Salvatierra's rural, hydrological, environmental and territorial development policies to work throughout the year.

\section{The water-rural development relationship based on constructivist environmental sociology}

In recent decades, an interest in the social sciences has grown to address the environmental problems that afflict human societies. 
The ecological crisis and the crisis of some paradigms of social sciences such as Marxism, functionalism or neoliberalism have laid the foundations to question anthropocentrism, developmentalism and the ideology of progress. The connections between ecology and society have been practically ignored, with the honorable exceptions of some natural and social scientists who, since the second half of the 19th century, glimpsed the significance of phenomena such as the consumption of finite resources of the earth's crust, the cycle of nutrients in agriculture and even the greenhouse effect. In recent times, the social sciences increasingly incorporate these connections, and the perception of the previously unsuspected ecological background of numerous political and social conflicts is becoming more frequent (Sampere and Riechman, 2004). Based on these changes in perception, the interdisciplinary collaboration between philosophy, social sciences and ecology resulted in the formulation of a diversity of hybrid disciplines such as environmental epistemology, environmental ethics, ecological anthropology, environmental history, environmental economics, political ecology, environmental pedagogy, ecological law, biogeography and environmental sociology. However, despite the advances made by environmental sociology in the United States, Canada, the United Kingdom and Japan, the sociological approach to the environmental issue is still limited in Mexico. In this sense, we consider that Mexican sociology is called to study environmental problems (solid waste, air pollution, loss of biodiversity or pollution and water scarcity) as crucial issues that merit diagnosis and public policy measures that they revert the environmental deterioration of municipalities and rural communities of the State of Guanajuato. Now, what important contributions can sociology make to the study of the environment, particularly the problem of water?

First, sociology can show how human social patterns have caused growing problems in the natural environment. That is, sociology can underline the connection between environmental problems and certain cultural values, and certain forms of political and economic organization. Second, sociology can monitor public reaction to many environmental issues, and can inform people's thoughts and fears (grounded or not) about these issues. Moreover, sociology analyzes why some categories of people are inclined to one side or the other of political debates on environmental issues. Third, sociology can explore what the environment means for people from different social groups (Macionis and Plummer, 1999, p.611).

In the case of the south of the State of Guanajuato, specifically in the municipality of Salvatierra, some studies have been carried out on the organizational principles in water management of some rural communities such as Urireo, the administration and historical-hydraulic tradition of the irrigation district 011 Alto Lerma(Mazabel and Díaz, 2011; Rodríguez, 2011), as well as studies on the participation and decision-making of users of communities attached to irrigation district 011 of Alto Lerma, from a gender perspective (Monsalvo, Zapata and Alberti, 2000). However, these studies have not explored other social actors that go beyond the users of the irrigation districts and modules, nor has the sociological analysis of environmental problems (contamination, overexploitation and scarcities of water), and much less have been linked to the study of rural development policies based on environmental sociology of a phenomenological or constructivist nature. The common denominator of the different variants of sociology of micro orientation lies in the creative dimension carried out by people in everyday life. Although, this sociology recognizes the externalist and objective existence of social reality, it emphasizes the subjective and constructivist dimension that social actors make of their reality. Berger and Luckmann (2003) argue that "reality is socially constructed" and that sociology must analyze the processes by which this occurs. The key terms of this thesis are "reality and knowledge". Reality defines it as a quality characteristic of the phenomena that we recognize as independent of our own volition, and knowledge as the certainty that the phenomena are real and that they have specific characteristics.

According to Lezama (2004) the environment and environmental damage, before being recognized as such, go through a process of valuation, filtering and social construction. This process of acceptance, perception and recognition is given by rules of knowledge, rules and symbols. Although there are studies on soil, air or water pollution, for example, that emphasize the physicochemical dimension and the technical aspects of pollution, the consequence of these disciplinary or partial approaches is that they have left out many aspects relevant to which have not been answered, as is the case of the social, symbolic, normative and political dimension of pollution, overexploitation and water scarcity. Social scientists maintain that there is a social dimension of environmental problems that have the same status of reality as those that emerge from their physical dimension. From this perspective a problem can have a physical existence, but if it is not socially perceived and assumed as such, it ends up being socially irrelevant. 
The sociological reflection of environmental problems aims to explain the social mechanisms that make it possible for certain problems of reality to acquire a special meaning andin some moment akes them appear on the public scene. Values, norms and social symbols appear as constitutive factors of environmental problems (Lezama, 2004).

On the other hand, the rural development policies that have been promoted in Mexico throughout its territory have operated on a sociocultural vision of water as an unlimited resource. In this sense, the country's agricultural, industrial and tourist production systems, for example, continue to be associated with a set of cultural patterns and forms of economic and political organization that result in a series of environmental consequences such as pollution, overexploitation and water scarcity. It should be noted that agricultural, industrial or tourism policies are not outsiders to the processes of social and political construction on the use of natural resources.

Now, how is rural development defined? On this concept there are as many definitions as authors. In that sense, some rural sociologists have defined it as:The economic and social process that takes place in traditional rural societies and that tends to improve the well-being of the rural population through actions such as: the introduction of modern technologies and the provision of social services such as health, education, culture, drinking water, drainage, roads, market centers, etc.; with the purpose of increasing the income and the standard of living of the majority of the rural population (Lozano, 2008: 40).

According to Lozano (2008), rural development requires interdisciplinary and inter-institutional actions focused on a specific community and region, trying to influence different aspects of the rural population, such as: income, education, health, food and living place. To achieve an impact on these aspects, the organization of the communities must be strengthened, in such a way that actions or productive projects, education programs, projects for health care and programs for improving housing conditions are promoted.

For its part, the Sustainable Rural Development Law defines Sustainable Rural Development as: The integral improvement of the social welfare of the population and of the economic activities in the territory included outside the nuclei considered urban in accordance with the applicable dispositions, assuring the permanent conservation of the natural resources, the biodiversity and the environmental services of said territory (Cámara de Diputados del H. Congreso de la Unión, 2012: 2).

After decades with reductionist approaches, the old vision of rural development focused on encouraging agricultural, livestock or forestry production has given way to the integral paradigm of sustainable rural development and the conservation of the natural and cultural heritage of farmers and indigenous communities of the country, whose Survival is increasingly threatened by global climate change, water stress, poverty, migration, aging and organized crime gangs.

The definition of rural development depends on the geographic and cultural context of the social actors that define it, as well as the disciplines that study it, because it is not the same to approach from the economy, political science, demography, anthropology or ecology, or from the perspective of countries as the United States, France, Brazil or China, or from an university, a ministry of agriculture, a farmers organization or an environmental organization. In that sense, all public policy of rural development obeys a process of social and political construction involving a series of institutions, political ideologies, cultural patterns and social actors, as well as a limited natural resource base such as water.

It should be noted that, internally, the municipalities and rural communities of Guanajuato present a diversity of institutions that are embodied in families, communal lands(the term in Spanish is "ejido"), businesses, political parties, water user associations (Technical Water Councils or COTAS, for example), agricultural producers, schools, clinics or health centers. However, urban areas and rural communities are also influenced or shaped by cultural patterns, policies and programs (loaded with norms, values and interests) of governmental institutions of the three levels of government: federal, state and municipal. In this sense, federal institutions such as the Ministry of Economy (Secretaría de Economía - SE), the National Water Commission (CONAGUA), the Ministry of Environment and Natural Resources (SEMARNAT) or the Ministry of Agriculture, Livestock, Rural Development, Fisheries and Food ( SAGARPA), as well as state and municipal officials, are some examples of social actors that influence the processes of social, political and cultural construction of the socio-environmental problems of southern Guanajuato, such as pollution, overexploitation and the shortage of water in the municipality of Salvatierra. 


\section{By way of conclusion}

The State of Guanajuato is no stranger to the national water crisis. In this sense, the agricultural sector has been the main responsible for the irrational use and pollution of water in the state. In the last decades of the 20th century and the first two decades of the 21st century the "urban Guanajuato" has experienced an accelerated demographic and real estate growth in several of its municipalities, has industrialized and urbanized, attracting automotive companies such as Honda, Toyota, Mazda, Ford, General Motors and Pirelli, which demand large quantities of water, often depriving their original owners: communal lands (ejidos) and farmers communities of "rural Guanajuato". On the other hand, if the policies of the Ministry of Agriculture and Rural Development, Sustainable Economic Development or Tourism of the State of Guanajuato, coincide in a social and political construction of water as an unlimited natural resource, it is clear that future state governments and Municipalities will face serious socio-environmental conflicts due to a myopic, irrational and suicidal vision of the water resource.

For its part, the municipality of Salvatierra is characterized for being largely dependent on agricultural activity. And like other municipalities in Guanajuato, it also presents problems of irrational water use due to unsustainable agricultural irrigation systems, in addition to the pollution of its groundwater. However, Salvatierra's situation is less serious than those affecting tourist cities such as Guanajuato or San Miguel de Allende. However, the municipality of Salvatierra and its area of rural development, will have to make effective the sustainable adjective, promoting a rational use of water in all sectors of the population, mainly in agricultural producers; in addition to implementing a series of educational policy measures that affect the ethical and civic education of children and young people through the institutionalization of environmental education and a water culture that guarantees the sustainability of the resource in the long term.

The proposal to analyze the problem of water in the municipality of Salvatierra from the constructivist environmental sociology represents an analytical model that should be replicated in the study of other socioenvironmental problems such as the management of solid waste, the use of agrochemicals, the junk food consumption, the effects of global climate change, the use of flora and fauna, the degradation of soils, ecotourism, deforestation, the absence of environmental education in schools and the ecological footprint.

\section{References}

Berger, P. y Luckmann, T. (2003). La construcción social de la realidad. Buenos Aires, Argentina: Amorrortu Editores.

Cámara de Diputados del H. Congreso de la Unión (2012). Ley de Desarrollo Rural Sustentable. México: Secretaría de Servicios Parlamentarios.

Casillas, A; Navarrete, A. y Segovia, J.G. (2012). La gestión del agua en Guanajuato. En CONABIO-IEEG. La biodiversidad en Guanajuato: Estudio de Estado. Vol. 1 (pp. 182-187). Guanajuato, México: CONABIOIEEG.

Cavanagh, J. et al. (2003). Alternativas a la globalización económica. Un mundo mejor es posible. Barcelona, España: Gédisa.

CEPAL (2010). Informe de la reunión de expertos. Análisis de los problemas de desarrollo rural en México. México: FAO.

Gobierno de Guanajuato (2013). Programa de Gobierno 2012-2018. Un gobierno con rostro humano y sentido social. Guanajuato, México: Gobierno de Guanajuato

IPLANEG (2012). Propuesta de plan municipal de Salvatierra. 12 de noviembre de 2015: seieg.iplaneg.net/pmd/doc/salvatierra/iii.documento/salvatierra_pmd.doc

Lezama, J. L. (2004). La construcción social y política del medio ambiente. México: El Colegio de México.

Lozano, A. (2008) Organización comunitaria y desarrollo rural: lecciones de una experiencia en Concepción Pápalo, Oaxaca. Tesis de Maestría. Departamento de Sociología Rural. México: Universidad Autónoma Chapingo.

Macionis, J. yPlummer, K. (1999). Sociología. España: Prentice Hall.

Mazabel, D. y Díaz, J. A. (2011). Principios organizativos en el manejo del agua en Urireo, Salvatierrra, Gto. En D. Mazabel y B. Rodríguez (coordinadores). Agua, cultura y desarrollo (pp. 95-118). México: Universidad de Guanajuato. 
Monzalvo, G.; Zapata, E. y Alberti, Pilar (2000). Participación y toma de decisiones de usuarios y usuarias en dos comunidades del Distrito de Riego 011: Alto Río Lerma, Guanajuato, México. En S. Buechler y E. Zapata (editoras). Género y manejo del agua y tierra en comunidades rurales de México (pp. 101-132). México: Colegio de Posgraduados-Instituto Internacional del Manejo del Agua.

Rodríguez, B. (2011). Módulo 01 y 02 del distrito de riego 011 Alto Lerma: tradición hidráulica en construcción. En D. Mazabel y B. Rodríguez (coordinadores). Agua, cultura y desarrollo (pp.119-143). México: Universidad de Guanajuato.

Sempere, J. y Riechmann, J. (2004). Sociología y medio ambiente. Madrid, España: Síntesis.

Shiva, V. (2003). Las guerras del agua. Privatización, contaminación y lucro. México: Siglo XXI. 